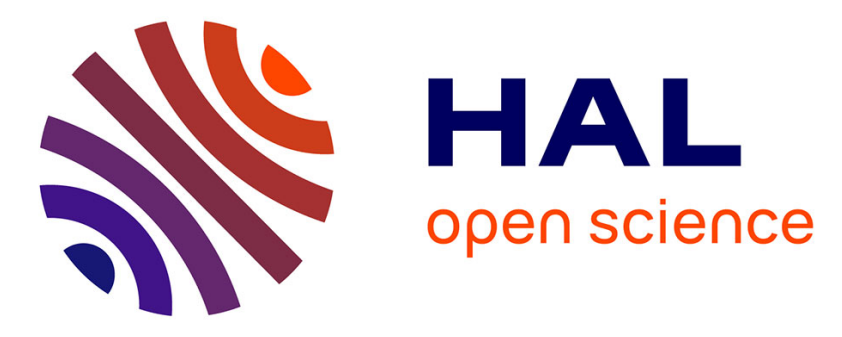

\title{
Multiple applications of polymers containing electron-reservoir metal-sandwich complexes
}

Xiong Liu, Amalia Rapakousiou, Christophe Deraedt, Roberto Ciganda, Yanlan Wang, Jaime Ruiz, Haibin Gu, Didier Astruc

\section{- To cite this version:}

Xiong Liu, Amalia Rapakousiou, Christophe Deraedt, Roberto Ciganda, Yanlan Wang, et al.. Multiple applications of polymers containing electron-reservoir metal-sandwich complexes. Chemical Communications, 2020, 56 (77), pp.11374-11385. 10.1039/D0CC04586A . hal-02997989

\section{HAL Id: hal-02997989 \\ https://hal.science/hal-02997989}

Submitted on 10 Nov 2020

HAL is a multi-disciplinary open access archive for the deposit and dissemination of scientific research documents, whether they are published or not. The documents may come from teaching and research institutions in France or abroad, or from public or private research centers.
L'archive ouverte pluridisciplinaire HAL, est destinée au dépôt et à la diffusion de documents scientifiques de niveau recherche, publiés ou non, émanant des établissements d'enseignement et de recherche français ou étrangers, des laboratoires publics ou privés. 


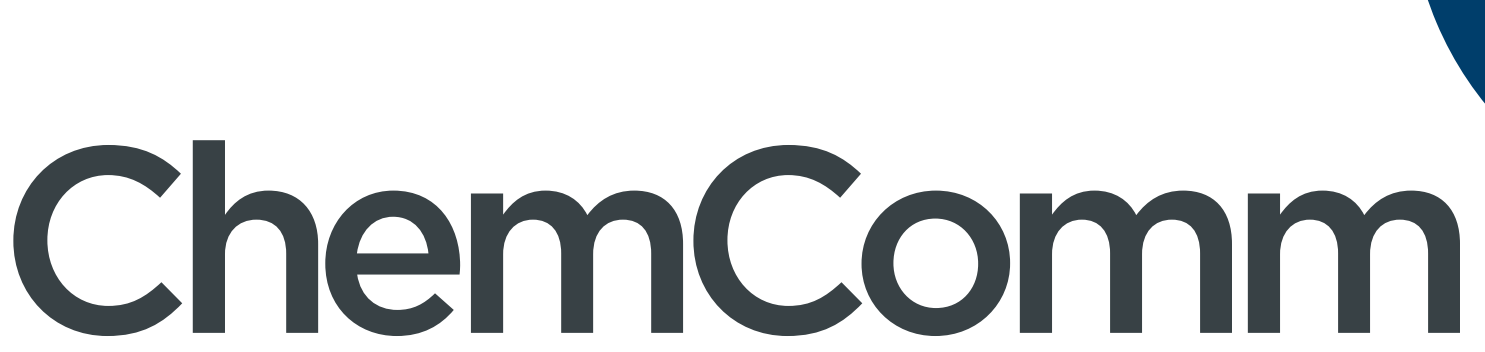

Chemical Communications

\section{Accepted Manuscript}

This article can be cited before page numbers have been issued, to do this please use: X. Liu, A.

Rapakousiou, C. Deraedt, R. Ciganda, Y. Wang, J. Ruiz, H. Gu and D. Astruc, Chem. Commun., 2020, DOI:
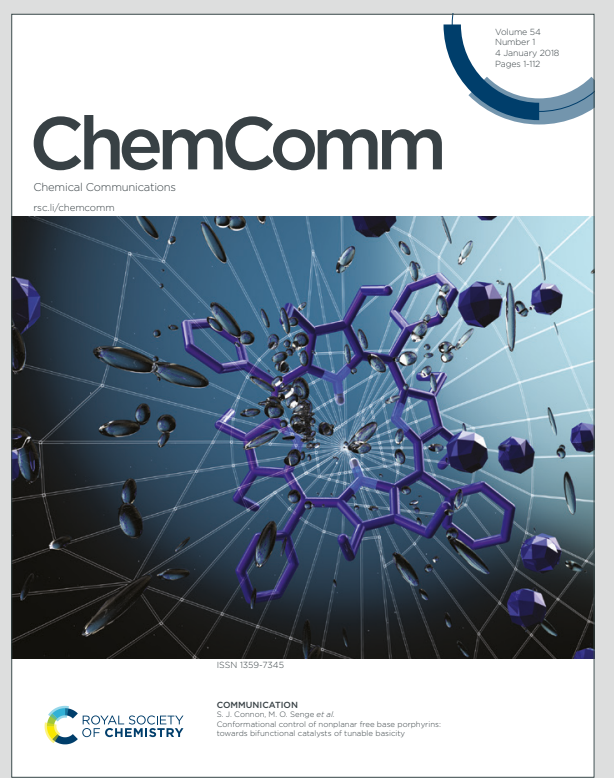

This is an Accepted Manuscript, which has been through the Royal Society of Chemistry peer review process and has been accepted for publication.

Accepted Manuscripts are published online shortly after acceptance, before technical editing, formatting and proof reading. Using this free service, authors can make their results available to the community, in citable form, before we publish the edited article. We will replace this Accepted Manuscript with the edited and formatted Advance Article as soon as it is available.

You can find more information about Accepted Manuscripts in the Information for Authors.

Please note that technical editing may introduce minor changes to the text and/or graphics, which may alter content. The journal's standard Terms \& Conditions and the Ethical guidelines still apply. In no event shall the Royal Society of Chemistry be held responsible for any errors or omissions in this Accepted Manuscript or any consequences arising from the use of any information it contains. 


\title{
ARTICLE
}

\section{Multiple Applications of Polymers Containing Electron-Reservoir Metal-Sandwich Complexes}

Received 00th January 20xx, Accepted 00th January 20xx

DOI: $10.1039 / \times 0 \times x 00000 x$

\author{
Xiong Liu, ${ }^{a}$ Amalia Rapakousiou, ${ }^{\mathrm{b}, \#}$ Christophe Deraedt, ${ }^{\mathrm{b}, \S}$ Roberto Ciganda, ${ }^{\mathrm{b}}$ Yanlan Wang, ${ }^{\mathrm{b}, \mathrm{f}}$ Jaime \\ Ruiz, ${ }^{\mathrm{b}}$ Haibin $\mathrm{Gu}^{\mathrm{a}, *}$ and Didier Astruc, ${ }^{\mathrm{b}, *}$
}

\begin{abstract}
Ferrocene-containing polymers have been investigated for more than six decades, and more recently modern synthetic methods have allowed the fabrication of precise polymers that contain a variety of transition-metal complexes. Trends are now oriented towards applications, such as optics, energy conversion and storage, electrochemistry, magnetics, electric conductors and biomedicine. Metal-sandwich complexes such as those of ferrocene type and other related complexes that present redox-robust groups in polymers, i.e. that are isolable under both their oxidized and reduced forms are of particular interest, because it is possible to address them using electronic or photonic redox stimuli for application. Our research groups have called such complexes Electron-Reservoirs and introduced them in the main chain or in the side chains of well-defined polymers. For instance, polymers with ferrocene in the main chain or in the side chain are oxidized to stable polycationic polyelectrolytes only if ferrocene is part of a biferrocene unit, because biferrocene oxidation leads to the biferrocenium cation that is stabilized by the mixed valency. Then a group of several redox-robust iron sandwich complexes were fabricated and incorporated in precise polymers including multi-block copolymers whose controlled synthesis and block incorporation was achieved for instance using ring-opening-metathesis polymerization. Applications of this family of Electron-Reservoir-containing polymers includes electrochemically-induced derivatization of electrodes by decorating them with these polymers, molecular recognition and redox sensing, electrochromics with multiple colours, generation of gold and silver nanoparticles of various size by reduction of gold (III) and silver (I) precursors and their uses for nanocatalysis towards depollution and biomedicine.
\end{abstract}

\section{Introduction}

Decisive progresses in polymerization techniques have recently allowed the emergence of smart stimuli-responsive polymers towards a wide range of applications. ${ }^{1-9}$ Among metal-containing polymers, redox-active ones deserve a special attention, because the redox switch involves an easily available stimuli using electrons or photons. ${ }^{3,4}$ The most common redox active polymers are ferrocene-containing polymers ${ }^{5,10-13}$ that are being increasingly used for energy-related, ${ }^{14,15}$ electrochemical, ${ }^{16-18}$ optical, ${ }^{19}$ biochemical ${ }^{20,21}$ and other materials applications. ${ }^{4,11,22-24}$ Ferrocene is chemically and electrochemically oxidized to the ferricenium cation at $\mathrm{E}^{\circ}=0.475 \mathrm{~V}$ vs. saturated calomel electrode (SCE) or 0.545 V vs. $\left[\mathrm{FeCp}_{2}\right]^{+/ 0}, \mathrm{Cp}{ }^{*}=\eta^{5}-\mathrm{C}_{5} \mathrm{Me}_{5}$, in $\mathrm{CH}_{2} \mathrm{Cl}_{2}$ with $0.1 \mathrm{M}$ [n$\left.\mathrm{Bu}_{4} \mathrm{~N}\right]\left[\mathrm{PF}_{6}\right]$ as the supporting electrolyte, but the value vs. SCE undergoes some variations depending on the medium, whereas $\left[\mathrm{FeCp}_{2}\right]^{+/ 0}$ is a more reliable, electrochemical reference that is independent from the medium. ${ }^{25}$ The electrochemical and other properties of ferrocenes have recently been reviewed. ${ }^{24}$ Unlike

a. Key Laboratory of Leather Chemistry and Engineering of Ministry of Education, Sichuan University, Chengdu 610065, China. E-mail: guhaibinkong@126.com (H. Gu).

b. ISM, UMR CNRS No 5255, Univ. Bordeaux, 33405 Talence Cedex, France. E-mail: didier.astruc@u-bordeaux.fr (D.Astruc). pentamethyl- and decamethylferricenium salts, ferricenium salts and mono or disubstituted derivatives are often fragile in solution. ${ }^{24}$ We have therefore designed and engineered "Electron Reservoirs", i.e. redox systems for which both the neutral and cationic forms are robust and easily isolable. They include a family of late-transitionmetal sandwich complexes spanning a very large range of redox potentials including a series of ferricenium-ferrocene systems (17e /18e), ${ }^{24}$ cobalticenium/cobaltocene $(18 \mathrm{e} / 19 \mathrm{e})^{25,26}$ and $\left[\mathrm{FeCp}\left(\mathrm{C}_{6} \mathrm{Me}_{6}\right)\right]^{+/ 0}\left(18 \mathrm{e} / 19 \mathrm{e} ; \mathrm{Cp}=\eta^{5}-\mathrm{C}_{5} \mathrm{H}_{5}\right),{ }^{27}$ all of which have been incorporated in the main polymer chain or as side chains of monoand poly-block polymers, including some dendronized polymers. Following our interest in Electron Reservoir-containing dendrimers in the 2000 's, ${ }^{28,29}$ in this feature article we discuss nanomaterials applications of Electron Reservoir-containing polymers disclosed in our group during the last six years. Polymers containing Electron Reservoir sandwich systems in the main chain or in the side chain have shown applications for electrochromes, polyelectrolytes, electrode modifiers, molecular recognition, nanoparticle stabilization, catalysts, hydrogels, and/or drug carriers (Fig. 1). Polymers are more likely than dendrimers to offer possibilities of these applications, because they are much more easily and quickly synthesized than the latter. 


\section{ARTICLE}

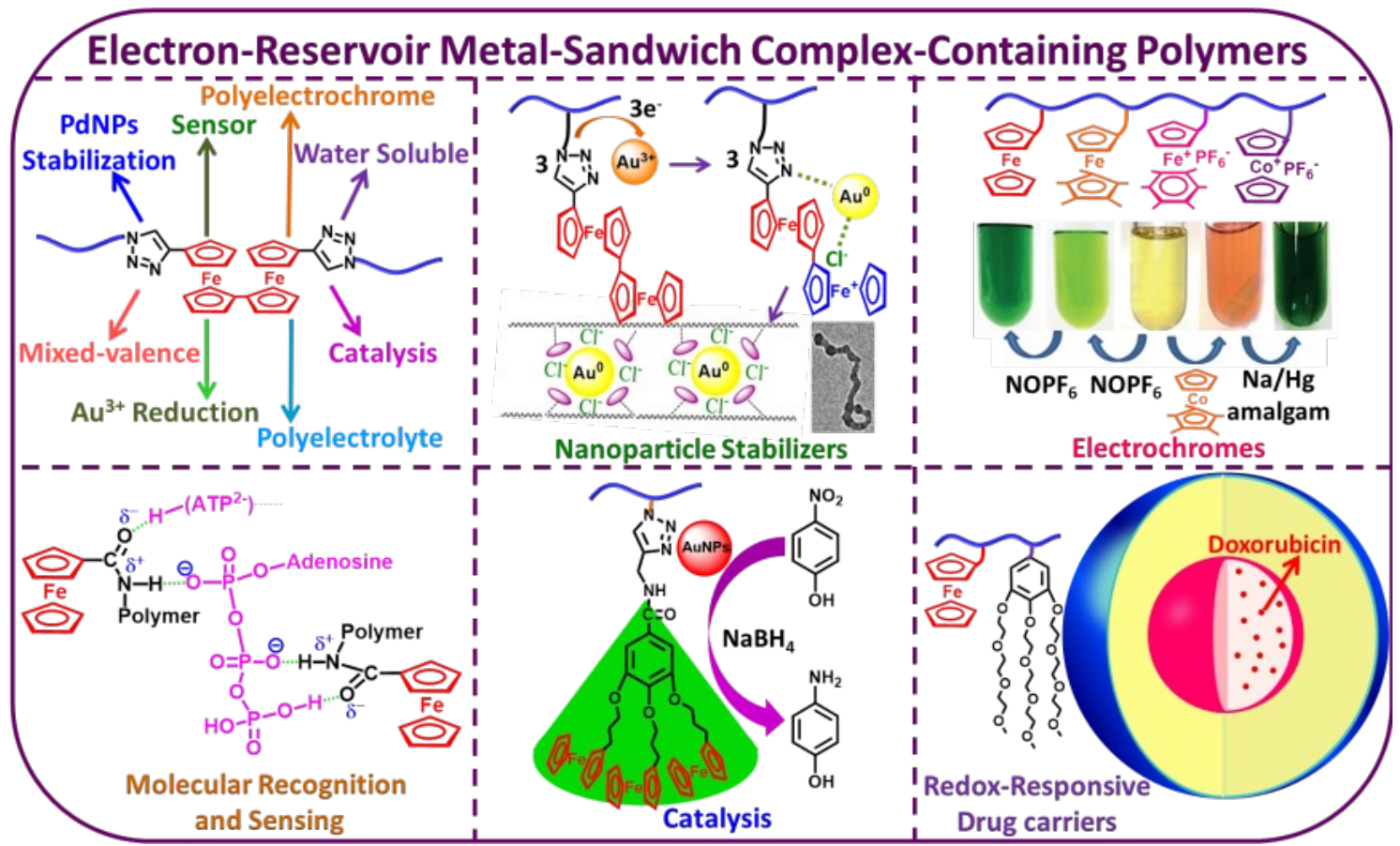

Fig. 1 The multiple applications of polymers containing electron-reservoir metal-sandwich complexes.

\section{Polymers containing biferrocene in the main} chain and multiple functions as polyelectrolyte, sensor, electrode modifier, nanoparticle stabilizer

\section{and catalyst}

The most well-known polymers containing ferrocene in the main chain are Manners's poly(ferrocenylsilanes). ${ }^{4,11}$ This research group has shown that these polymers have a high refractive index and form fibres, films and nanoporous membranes; they are redoxactive gels and serve as precursors to magnetic ceramics. They also find other applications in nanotemplating and nanolithography. Moreover, they take part in metalloblock copolymers that form core-shell nanoparticles in specific solvents. These rich families of functional ferrocene-containing polymers have been reviewed. ${ }^{4,11}$ Polymers containing an Electron Reservoir stabilizing Fe"l'/Fe" redox system in the main chain have been fabricated in our group ${ }^{30,31}$ by "click" polycondensation of diethynylbiferrocene $1^{32,33}$ with bisazido poly(ethylene glycol) ${ }^{34}$ (PEG) monomers $2\left(400 \mathrm{~g} \mathrm{~mol}^{-1}\right)$ or 3 $\left(1000 \mathrm{~g} \mathrm{~mol}^{-1}\right)$ or catalysed by a mixture of $\mathrm{CuSO}_{4} \cdot \mathrm{H}_{2} \mathrm{O}$ and sodium ascorbate in $\mathrm{THF} / \mathrm{H}_{2} \mathrm{O}$ at $40^{\circ} \mathrm{C}$ for 2 days (Fig. 2). ${ }^{35}$ These easily synthesized orange-red biferrocene polymers of low polydispersity of 1.2 to 1.3 (determined by size exclusion chromatography, SEC) are soluble in $\mathrm{CH}_{2} \mathrm{Cl}_{2}$, and their solubility in water and other aqueous solvents depends on the length of the solubilizing PEG chain. Upon oxidation by one equiv. $\left[\mathrm{FeCp}_{2}\right]\left[\mathrm{BF}_{4}\right]$ or $\left[\mathrm{FeCp}_{2}\right]\left[\mathrm{PF}_{6}\right]$ in $\mathrm{CH}_{2} \mathrm{Cl}_{2}$, robust blue-green mixed-valent biferrocenium polyelectrolytes soluble in $\mathrm{MeCN}$ are obtained. In these latter polymers, the stereoelectronic influence of the ferrocenyl group greatly stabilizes the ferricenium neighbour. With these $\mathrm{BF}_{4}{ }^{-}$salts, both the ferrocenyl $(\mathrm{Fc})$ and ferricenium $\left(\mathrm{Fc}^{+}\right)$band are observed at $818 \mathrm{~cm}^{-1}\left(\mathrm{~V}_{\mathrm{Fc}}\right)$ and $832 \mathrm{~cm}^{-1}\left(\mathrm{~V}_{\mathrm{Fc}+}\right)$ respectively in the FTIR spectrum indicating localized mixed valency at the IR time scale $\left(10^{-13} \mathrm{~s}\right)$. Mössbauer spectroscopy at zero field and $78 \mathrm{~K}$ verifies this localized mixed valency at the Mössbauer time scale $\left(10^{-7} \mathrm{~s}\right)$ by the appearance of both the classical ferrocene quadrupole doublet and the ferricenium broad band. ${ }^{30}$ Cyclic voltammetry (CV) using a $\mathrm{Pt}$ anode in $\mathrm{CH}_{2} \mathrm{Cl}_{2}$ with $\left[n-\mathrm{Bu}_{4} \mathrm{~N}\right]\left[\mathrm{PF}_{6}\right]$ as electrolyte shows two wellseparated chemically and electrochemically reversible waves near $0.4 \mathrm{~V}$ and $0.8 \mathrm{~V}$ vs. $\left[\mathrm{Cp}^{*}{ }_{2} \mathrm{Fe}\right]^{+/ 0}, \mathrm{Cp}^{*}=\eta^{5}-\mathrm{C}_{5} \mathrm{Me}_{5}$ (Fig. $3 \mathrm{a}$ ), this large separation between these two waves due to electrostatic and electronic effects between the two nearby ferrocenyl units of biferrocene allowing the straightforward and selective synthesis of the mixed-valent $\mathrm{Fe}^{\mathrm{II}}$-Fe $\mathrm{F}^{\text {III }}$ polyelectrolytes indicated above. On the other hand, the different biferrocenyl groups are far, thus independent, from one another, which avoids mutual influence on the $\mathrm{CV}$. The number of monomer units in the polymers was determined using Bard-Anson's method ${ }^{36}$ and was found to be $62 \pm$ 1 for $\mathbf{4}$ and $131 \pm 20$ for $\mathbf{5}$. For the less soluble polymer $\mathbf{4}$, scanning 


\section{ARTICLE}
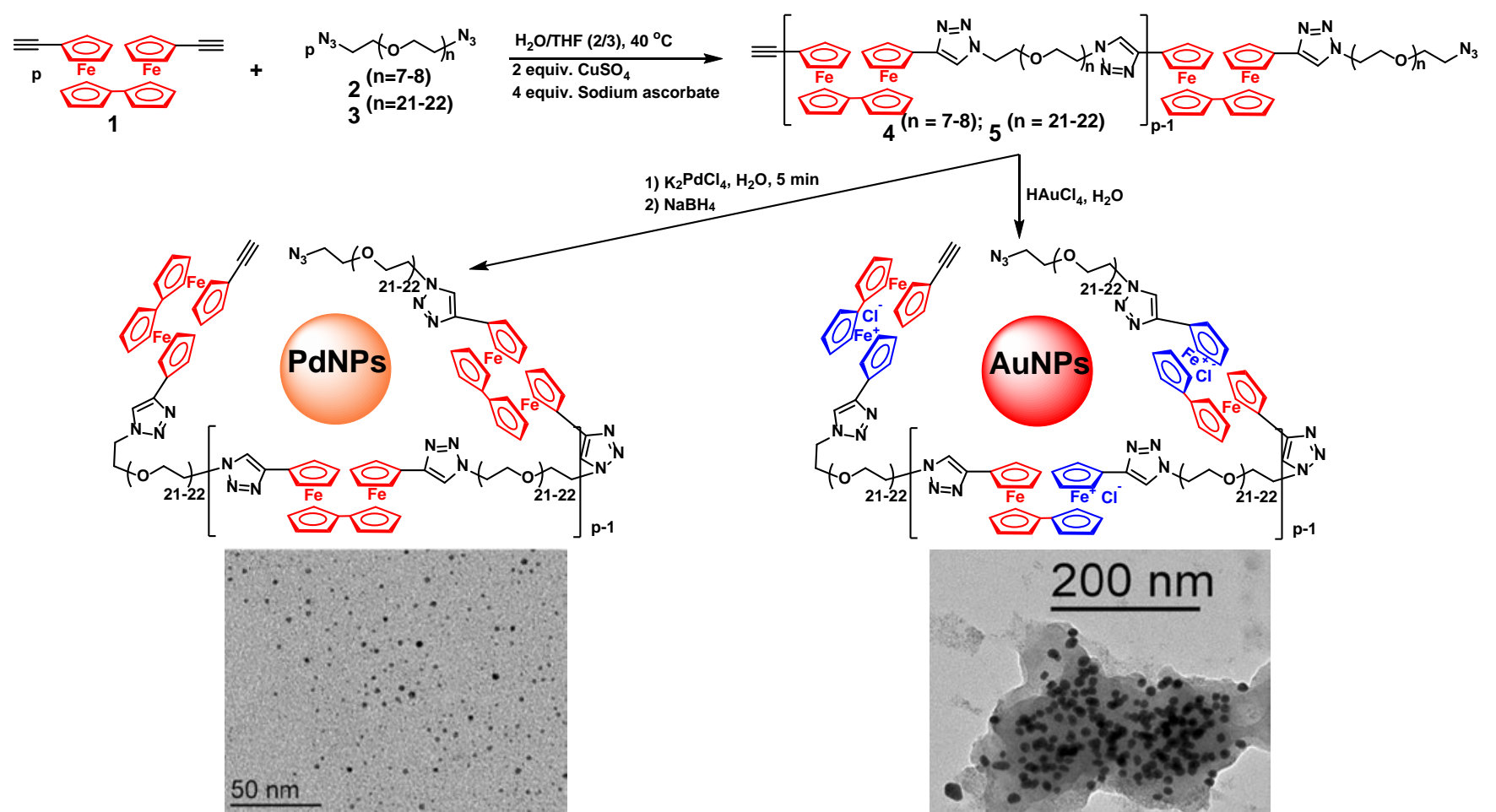

Fig. 2 Synthetic route of polymers 4 and $\mathbf{5}$ and preparation of PdNPs and AuNPs with TEM images. Reproduced with permission from ref 30. Copyright 2014 Wiley-VCH Verlag GmbH \& Co. KGaA, Weinheim.

(a)
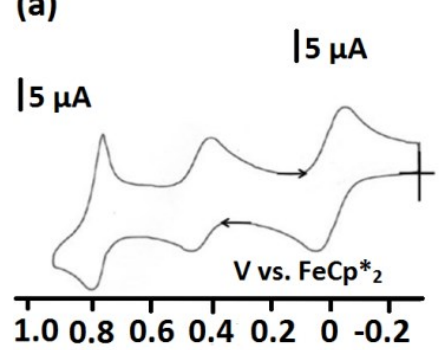

(c)
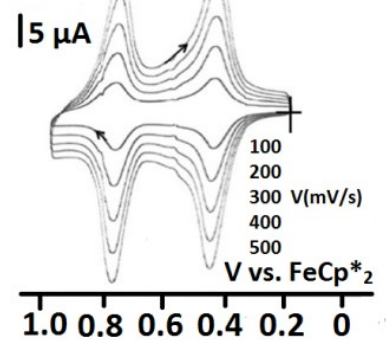

(b)
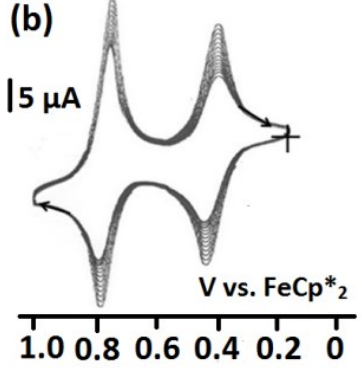

(d)

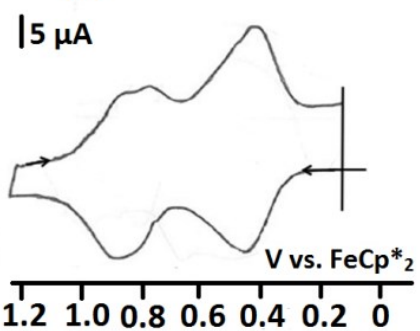

Fig. 3. a) CV of 4. b) CVs indicating the progressive adsorption of 4 on the electrode. c) CVs of the polymer 4 modified electrode at different scan rates. d) CV of $\mathbf{4}$ after adding $\mathrm{Pd}(\mathrm{OAc})_{2}$. Reproduced with permission from ref 30. Copyright 2014 Wiley-VCH Verlag GmbH \& Co. KGaA, Weinheim.

potentials around these two CV waves allows adsorption leading to the progressive formation of a polymer-derivatized electrode as witnessed by the increase of the wave intensities after each scan (Fig. $2 \mathrm{~b}, \mathrm{c}$ ). In the presence of one equiv. $\mathrm{Pd}(\mathrm{OAc})_{2}$ per biferrocene unit, the second $\mathrm{CV}$ ferrocenyl wave of this modified electrode splits by $70 \mathrm{mV}$ showing recognition of $\mathrm{Pd}(\mathrm{OAc})_{2}$ due to 1,3-triazole ligand binding to $\mathrm{Pd}(\mathrm{II})$ in synergy with $\mathrm{Fe}(\mathrm{III})$-acetate interaction (Fig. 3d). This recognition is also reflected in ${ }^{1} \mathrm{H}$ NMR using a $\mathrm{CDCl}_{3}-\mathrm{MeOD}$ solvent mixture by a shift of the acetate signal maximized at a $1 / 1$ stoichiometry between the biferrocene polymer unit and $\mathrm{Pd}(\mathrm{OAc})_{2}$. This type of redox recognition using electrochemistry and ${ }^{1} \mathrm{H}$ NMR has been pioneered and developed with a variety of ferrocenecontaining endo-receptors by Beers' group. ${ }^{37-39}$

Monitoring the coordination of the click polymer triazole ligands to metal ions by $\mathrm{CV}$ and ${ }^{1} \mathrm{H}$ NMR is very useful in catalysis. This was exemplified by both coordination of $\mathrm{Pd}(\mathrm{II})$ in $\mathrm{Pd}(\mathrm{OAc})_{2}$ and $\mathrm{Au}(\mathrm{III})$ in $\mathrm{HAuCl}_{4}$ (Fig. 2). Following coordination upon mixing the metal derivative and the polymer with this stoichiometry for triazole complexation, reduction to small metal (0) nanoparticles (MNPs) is possible either in the presence or absence of $\mathrm{NaBH}_{4}$ because of synergistic stabilization of these NPs by triazole binding onto the MNP surface combined with steric polymer bulk. These small palladium nanoparticles (PdNPs) (diameter size measured by 


\section{ARTICLE}

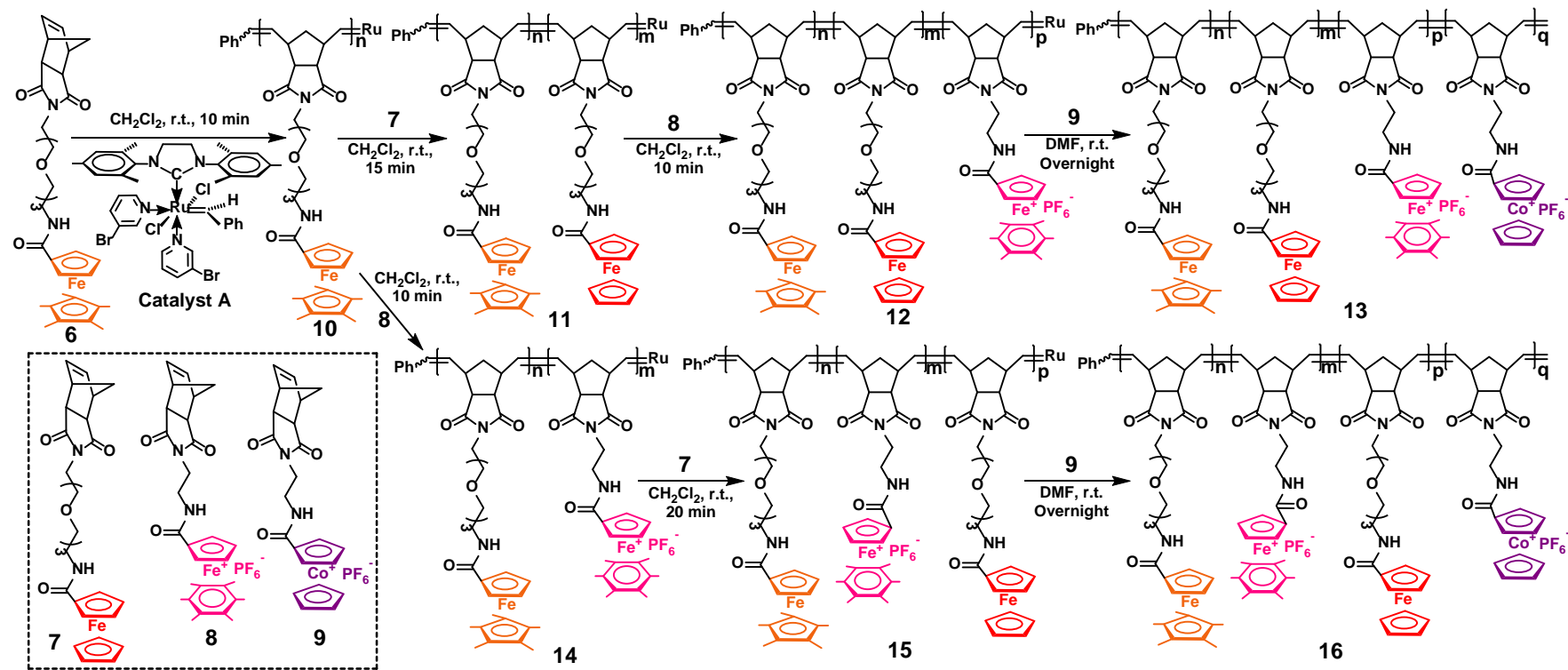

Fig. 4 Synthetic routes of metallocene-containing tetra-block copolymers.

TEM: $2.3 \pm 0.6 \mathrm{~nm}$ ) are catalytically very active. For instance, with the polymer containing long PEG linkages, Suzuki-Myaura cross coupling reactions between deactivated bromoarenes and phenylboronic acid were conducted quantitatively in the green solvent EtOH- $\mathrm{H}_{2} \mathrm{O}$ : $1-1$ at $80{ }^{\circ} \mathrm{C}$ with only $20 \mathrm{ppm}$ of these PdNPs. With 4-bromoacetophenones, the amount of catalyst was even decreased down to $2 \mathrm{ppm}$ Pd from PdNPs with $82 \%$ yield. In the presence of the same polymer, addition of $\mathrm{HAuCl}_{4}$ (stoichiometry: polymer-HAuCl 4 : 1-3) leads to the formation of purple gold nanoparticles (AuNPs), while the polymer is oxidized to the mixedvalent Fe" $\mathrm{Fe}^{\text {III }}$ polymer stabilizing these AuNPs (plasmon band: 534 $\mathrm{nm}$; diameter size measured by TEM: $12 \pm 2 \mathrm{~nm}$ ) together with the chloride ligands. These AuNPs (1.2\%) catalyse the reduction by $\mathrm{NaBH}_{4}$ of 4-nitrophenol (4-NP) to 4-aminophenol (4-AP), the reaction being complete with pseudo-first order kinetics in less than $6 \mathrm{~min}\left(\mathrm{k}_{\mathrm{app}}=6 \times 10^{-3} \mathrm{~s}^{-1}\right)$. Smaller AuNPs and even faster catalysis are obtained if $\mathrm{HAuCl}_{3}$ is added to the polymer/ $\mathrm{NaBH}_{4}$ mixture (vide infra). Related properties are also observed with the biferrocene Electron Reservoir anchored by a similar "click" reaction between mono ethynyl biferrocene and a polymerizable fragment terminated by an azido group leading to a polymer with biferrocenyl in the polymer side chain (vide infra)..$^{32}$ Manners' group has also pioneered AgNPs encapsulated on ferrocene-containing block copolymers, ${ }^{40}$ and biferrocene systems have recently also been used in single-molecule electronics. ${ }^{41}$

\section{Polymers containing Electron-Reservoir metal- sandwich systems in the side chain}

Polymers containing ferrocene in the side-chain have long been reported and studied for their properties..$^{4,5,10-13}$ Our initial studies on polymers containing ferrocene in the side chain concerned the dendronization of polymers and the polymerization of dendrons. In both cases the tripodal dendrons contained three ferroceneterminated branches, and the polymers were synthesized by AIBNinitiated radical polymerization of para-substituted styrenes yielding the first ferrocene-containing dendronized polymers. ${ }^{42}$ In these examples of dendronized polymers, ${ }^{43}$ the polymerization reactions were not controlled, however. Therefore, we turned to classic ring-opening-metathesis polymerization (ROMP) of norbornene derivatives using Grubbs'3rd generation metathesis catalyst A (Fig. 4) that has been shown to be stable in air and water and to present wide applicability. ${ }^{3}$ The norbornene derivative was first functionalized with a linker that was then attached to an Electron-Reservoir metal-sandwich termini either by an amide linkage or by $\mathrm{Cu}(\mathrm{I})$-catalysed click reaction. The Electron-Reservoir systems included ferrocene, biferrocene, ferrocene-containing dendrons, $\left[\mathrm{CpFeC}_{6} \mathrm{Me}_{6}\right]\left[\mathrm{PF}_{6}\right]$ or $\left[\mathrm{CoCp}_{2}\right]\left[\mathrm{PF}_{6}\right]$. Since this $\mathrm{Ru}$ metathesis initiator has an extremely fast initiation rate, yields and conversions were quantitative in the absence of solubility problem, the number of monomer units in the polymer being equal to the monomer: initiator ratio, at least when this ratio was not $>50$. Solubility problems were solved by adoption of longer links or prior introduction of a monomer block containing triethylene glycol termini. Monomers containing a 1,3-triazole ring were polymerized more slowly than when the link was the amido group due to reversible coordination of 1,3-triazole to the Ru center. ${ }^{3}$ Thus, the method allowed the facile synthesis of block co-polymers upon 

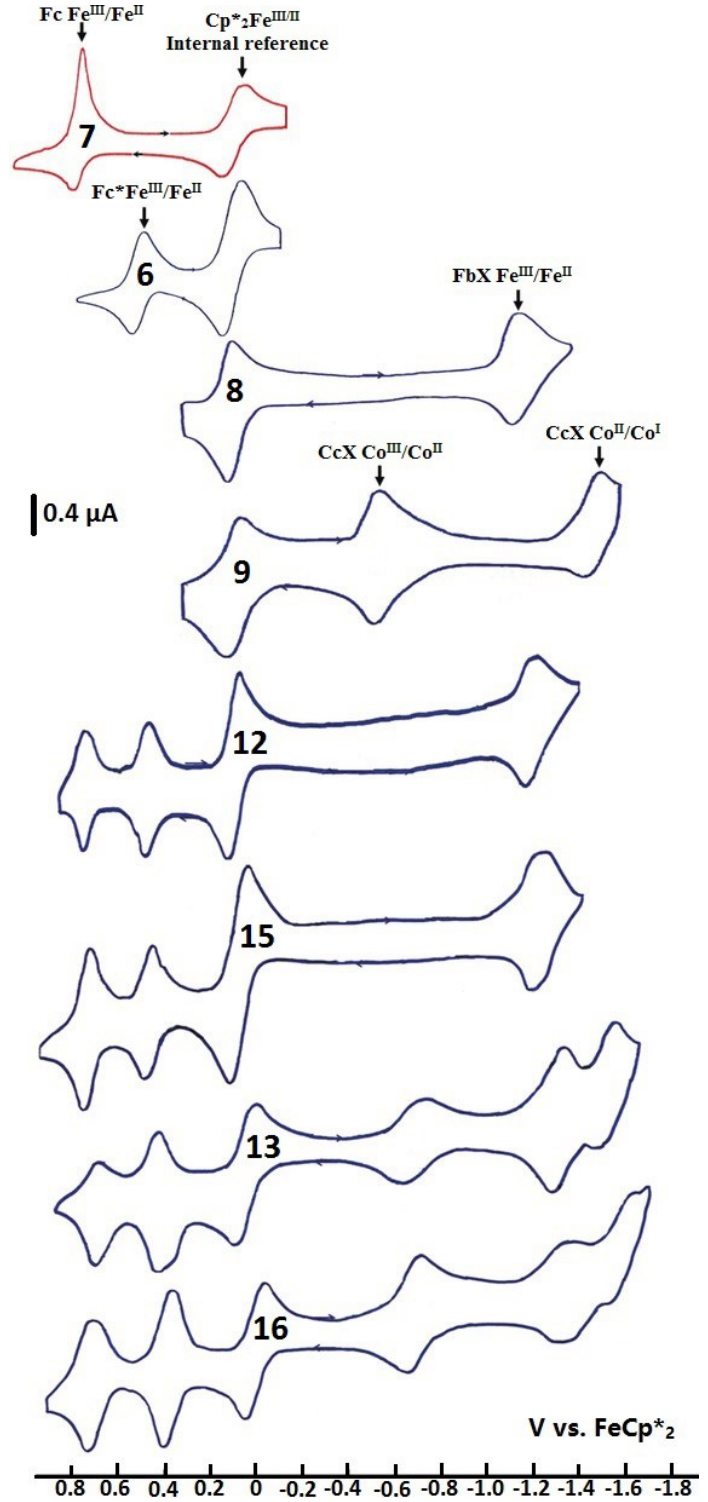

Fig. 5 CVs of polymers $6,7,8,9,12,13,15$ and 16. Reproduced with permission from ref 45 . Copyright 2018 Wiley-VCH Verlag GmbH \& Co. KGaA, Weinheim.

using successively distinct norbornene derivatives as monomers, the order of block introduction taking into account the solubility aspect (more soluble monomers were introduced first). Typical syntheses of mono-, di-, tri- and tetrablock metallo-co-polymers are represented in Fig. 4. The MWs of the polymers were determined by MALDI-TOF MS, ${ }^{1} \mathrm{H}$ NMR-based end-group analysis and the electrochemical Bard-Anson method, whereas size exclusion chromatography (SEC) suffered from lack of a suitable reference. Nevertheless, the polydispersity indices values of the polymers were found by SEC to be relatively small (1.05-1.13).

\subsection{Electrochromes}

The ferrocene-ferricenium couple has long presented an excellent example of electrochrome, as illustrated by Manners' ferrocenylsilane polymers, ${ }^{4,11}$ and this system continues to attract interest. ${ }^{44}$ The variety of Electron-Reservoir redox potentials on the electrochemical scale and the possibility of well-controlled access to
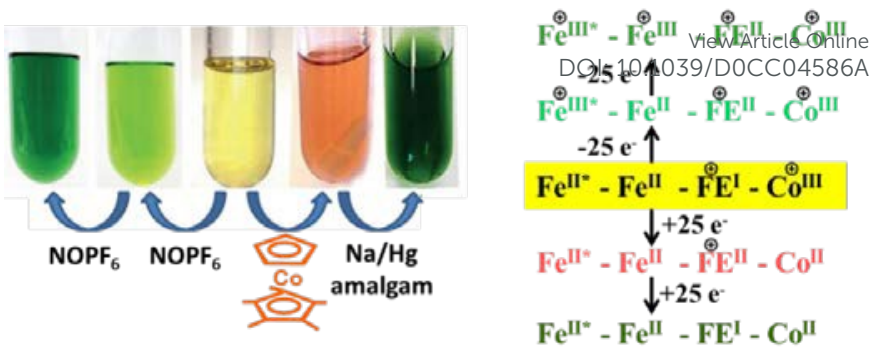

Fig. 6 Selective colour changes and the electron transfers of $\mathbf{1 3}$ after addition of different stoichiometric redox reagents. Reproduced with permission from ref 45. Copyright 2018 Wiley-VCH Verlag $\mathrm{GmbH} \&$ Co. KGaA, Weinheim.

multiple blocks of copolymers offer a unique possibility to extend the number of accessible colours of the visible spectrum providing rich electrochromes. ${ }^{45}$ For this purpose, tetrablock copolymers of the type 13 and 16 were synthesized as shown in Fig. 4, and exergonic electron transfer with each redox system using appropriate redox reagents was designed and achieved. CV analysis showed that tetrablock copolymers $\mathbf{1 3}$ and $\mathbf{1 6}$ showed chemically and electrochemically reversible waves that were well matched with the $\mathrm{CV}$ waves observed in the corresponding monomers and polymer intermediates, and the cathodic waves of the cationic sandwich groups were slightly broadened owing to the electrostatic effects (Fig. 5). Benefiting from the multiple redox behaviour, the tetrablock copolymer $\mathbf{1 3}$ showed selective colour variations after adding these redox reagents as shown in Fig. 6 . After the addition of mostly colourless $\mathrm{NO}^{+} \mathrm{PF}_{6}^{-}\left(E_{1 / 2}=1.54 \mathrm{~V}\right)$, the solution of 13 varied from yellow to olive-green because of the oxidation of PFM $\left(E_{1 / 2}=\right.$ $0.36 \mathrm{~V})$ block to pentamethylferricenium (PMFium) one. Upon continuing to add $\mathrm{NO}^{+} \mathrm{PF}_{6}{ }^{-}$to the solution, Fc groups $\left(E_{1 / 2}=0.62 \mathrm{~V}\right)$ were oxidized to ferricenium units, leading to a greener solution. Selective reductions also triggered twice to colour change. By adding light-brown pentamethylcobaltocene $\left(E_{1 / 2}=-1.10 \mathrm{~V}\right)$ to the solution of 13 , the cobalticinium groups were reduced to give an orange solution. Subsequent addition of $1 \% \mathrm{Na} / \mathrm{Hg}\left(E_{1 / 2}=-1.61 \mathrm{~V}\right)$ reduced the cationic $\left[\mathrm{FeCp}\left(\eta^{6}-\mathrm{C}_{6} \mathrm{Me}_{6}\right)\right]^{+}$centres $\left(E_{1 / 2}=-1.49 \mathrm{~V}\right)$ to generate the deep-green solution. In addition, the use of $\mathrm{HAuCl}_{4}$ to oxidize polymer $\mathbf{1 3}$ also could generate a distinct olive-green colour that was gradually changed to light purple. The olive-green colour was due to the formation of an $A u(I)$ intermediate; however, the light-purple colour was due to the conversion of the $\mathrm{Au}(\mathrm{I})$ intermediate to AuNPs with a $130 \mathrm{~nm}$ core.

\subsection{Molecular recognition and sensing of ATP using simple ferrocene-containing polymers.}

Ferrocene-containing endo ${ }^{39-41,46}$ and macromolecular exoreceptors ${ }^{17,29,47}$ have frequently been used as sensors to detect anions due to rapid heterogeneous electron transfer, ${ }^{48,49}$ easily accessible oxidation potential, and high stability at the electrochemical time scale of both the reduced and oxidized forms. ${ }^{50}$ The advantage of well-controlled polymers is that the number of ferrocene units is designed at will, and a second solubilizing block containing for instance tri-(ethylene glycol) 


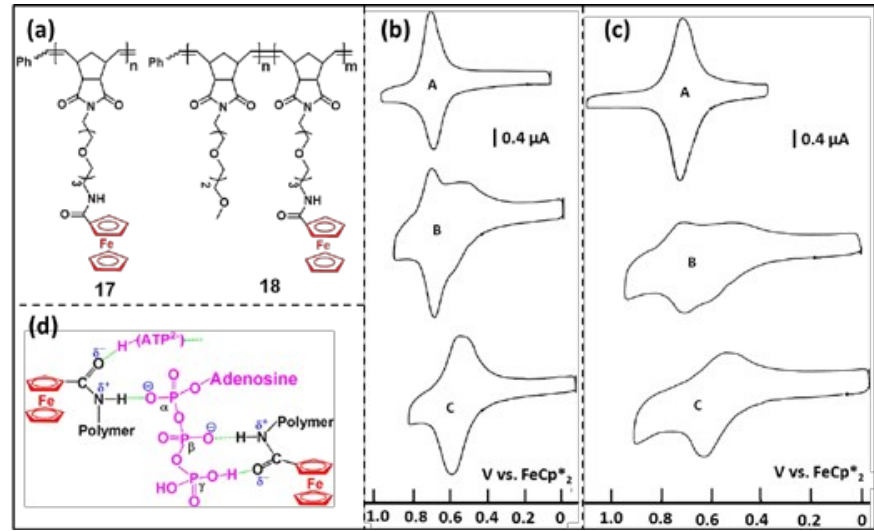

Fig. 7 (a) Molecular structures of 17 and 18. (b,c) CVs of the functionalized Pt electrodes with 17 and 18, respectively, before (A), during (B) and after (C) the addition of $\left[n-\mathrm{Bu}_{4} \mathrm{~N}\right]_{2}[$ ATP]. (c) $\mathrm{H}-$ bonding interactions between $\mathrm{ATP}^{2-}$ and 17. Reproduced with permission from ref 51. Copyright 2014 American Chemical Society.

termini allows to control the solubility of the nanomaterials that is crucial for electrode adsorption and derivatization.

With the ferrocene-containing polymer 17 (Fig. 7a), a functionalized Pt electrode was used to quantitatively detect adenosine triphosphate anion (ATP2-), a DNA fragment. When $[n-$ $\left.\mathrm{Bu}_{4} \mathrm{~N}\right]_{2}[$ ATP] was added into the electrochemical cell equipped with the polymer $\mathbf{1 7}$ functionalized electrode, a new wave was observed at a potential less positive than that for the original one (Fig. $7 \mathrm{~b}$ ). Then, the intensity of the original wave was reduced, whereas that of the new wave was enhanced. The sensing is based on the $\mathrm{H}$ bonding interactions between ATP2- and $\mathbf{1 7}$ (Fig. 7d). Interestingly, the potential difference between the original wave and the new one with the amphiphilic diblock copolymer 18 (Fig. 7a) functionalized Pt electrode is $20 \mathrm{mV}$ higher than that acquired with the polymer $\mathbf{1 7}$ functionalized electrode (Fig. 7c). Compared to the polymer 17 modified Pt electrode, the copolymer 18 modified Pt electrode exhibited a better effect in the recognition of ATP2anions. This better function of copolymer $\mathbf{1 8}$ modified electrode is probably due to the encapsulation effect of the triethylene glycol block at the location of the $\mathrm{H}$-bonding interactions. ${ }^{51}$

\subsection{Formation of Gold and Silver Nanoparticles, Nanosnakes, and Catalysis}

There are essentially two ways to produce gold and silver nanoparticles (NPs) from macromolecules containing ferrocene or biferrocene polymers: (i) mixing the polymer with $\mathrm{HAuCl}_{4}$ or $\mathrm{AgNO}_{3}$ and (ii) adding $\mathrm{HAuCl}_{4}$ or $\mathrm{AgNO}_{3}$ to the mixture of the polymer and a strong reduction agent such as $\mathrm{NaBH}_{4}{ }^{40,51-54}$ In the first case, the NPs are large (10-30 nm) and may be of interest in nanomedicine, for instance for theranostics; whereas, in the second case the NPs are small $(2-5 \mathrm{~nm})$ and may be of interest for nanocatalysis. ${ }^{55,56}$ Whereas polymers with ferrocene-triazolyl groups on the side chain reacted with $\mathrm{HAuCl}_{4}$ leading to AuNP aggregation, with biferrocene triazolyl groups on the side chain, stabilization was much more efficient yielding the $35 \mathrm{e}$ - biferrocenium polymer-stabilized AuNPs. This reaction of biferrocene triazolyl-containing polymers $\mathbf{1 9}$ or $\mathbf{2 0}$ (Fig. 8a) with $\mathrm{HAuCl}_{4}$ led to the formation of polymer nanosnakes after incubation for one week (Fig. 8b). ${ }^{31,53}$ The isolated nanosnakes (a)
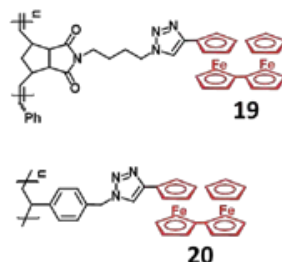

(b)
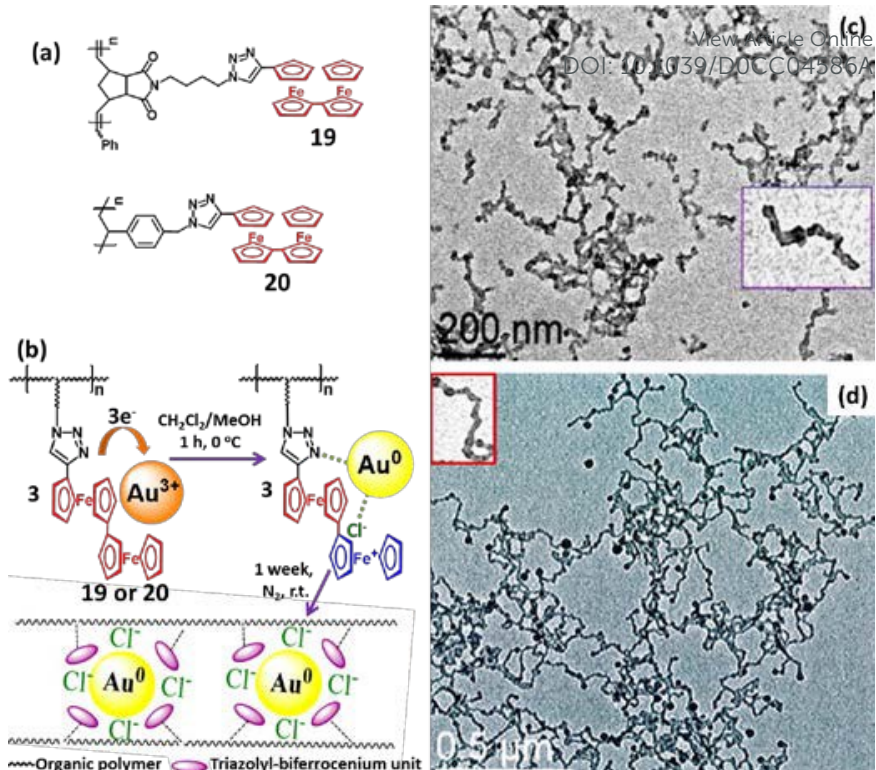

Fig. 8 (a) Molecular structure of 19 and 20. (b) Preparation of AuNPs using $\mathbf{1 9}$ or $\mathbf{2 0}$ as a reducing agent and stabilizer. TEM images of AuNPs obtained from 19 (c) and 20 (d). Reproduced with permission from ref 31. Copyright 2014 American Chemical Society.

obtained from polymer 19 had a thickness of approximately $8.7 \mathrm{~nm}$, a length of around $210 \mathrm{~nm}$, and encapsulated eleven spherical AuNPs of about $13.5 \mathrm{~nm}$ with inter-AuNP distances of approximately $5.2 \mathrm{~nm}$ (Fig. 8c). The use of polymer 20 as a reducing agent and stabilizer gave nanosnakes with a thickness of around 8.5 $\mathrm{nm}$, a length of about $269 \mathrm{~nm}$. Fourteen AuNPs are loaded with an approximate width of $14.5 \mathrm{~nm}$ and inter-AuNP distances of around $5.2 \mathrm{~nm}$ (Fig. 8d). The generation of AuNP nanosnakes is attributable to the electrostatic repulsions between biferrocenium groups. It is remarkable that when the same bis(triazolylferrocene) fragment was in the main chain (vide supra, Fig. 2), the nanosnakes were not observed, pointing the essential need of the flexibility of the biferrocene groups in the bimetallocene-containing branches of the polymers. ${ }^{31,53}$

The pentamethylcyclopentadienyl ligand strongly stabilizes PMFium, and by oxidation of polymer $\mathbf{2 1}$ using $\mathrm{Ag}(\mathrm{I})$ or $\mathrm{Au}(\mathrm{III})$ salts, PMFium-based polymer-stabilized silver nanoparticles (AgNPs) or AuNPs were obtained as shown in Fig. 9.52 Polymer 21 was oxidized with $\mathrm{AgPF}_{6}$ in two routes (Fig. 9a). In this first route, $\mathrm{Ag}(\mathrm{I})$ was instantaneously reduced to $\mathrm{Ag}(0)$ accompanied by a colour variation from light yellow to light-purple, and the resulting AgNPs had the size of $3 \pm 1 \mathrm{~nm}$. However, this process was slowed down in the presence of $\mathrm{I}_{2}$, and then it took $2 \mathrm{~h}$ to observe the colour variation from light yellow to light brown. AgINPs and AgNPs were found in this system. Oxidation of $\mathbf{2 1}$ using $\mathrm{Au}(\mathrm{III})$ formed a green $\mathrm{Au}(\mathrm{I})$ intermediate that led to the pink AuNPs $(27 \pm 3 \mathrm{~nm})$ after overnight stirring. Alternatively, smaller AuNPs $(4 \pm 1 \mathrm{~nm})$ were obtained by reduction of the $\mathrm{Au}(\mathrm{I})$ intermediate with $\mathrm{NaBH}_{4}$. This $\mathrm{Au}(\mathrm{I})$ intermediate became stable in the presence of the triazole ligand 22 that coordinated $\mathrm{Au}(\mathrm{I})$, making it more electron rich, which prevented reduction to $\mathrm{Au}(0)$ (Fig. $9 \mathrm{~b})$. So, the $\mathrm{Au}(\mathrm{I})$ intermediate was not further reduced to AuNPs in the presence of this ligand after overnight stirring. In order to reduce such $\mathrm{Au}(\mathrm{I})$ intermediate, 


\section{ARTICLE}
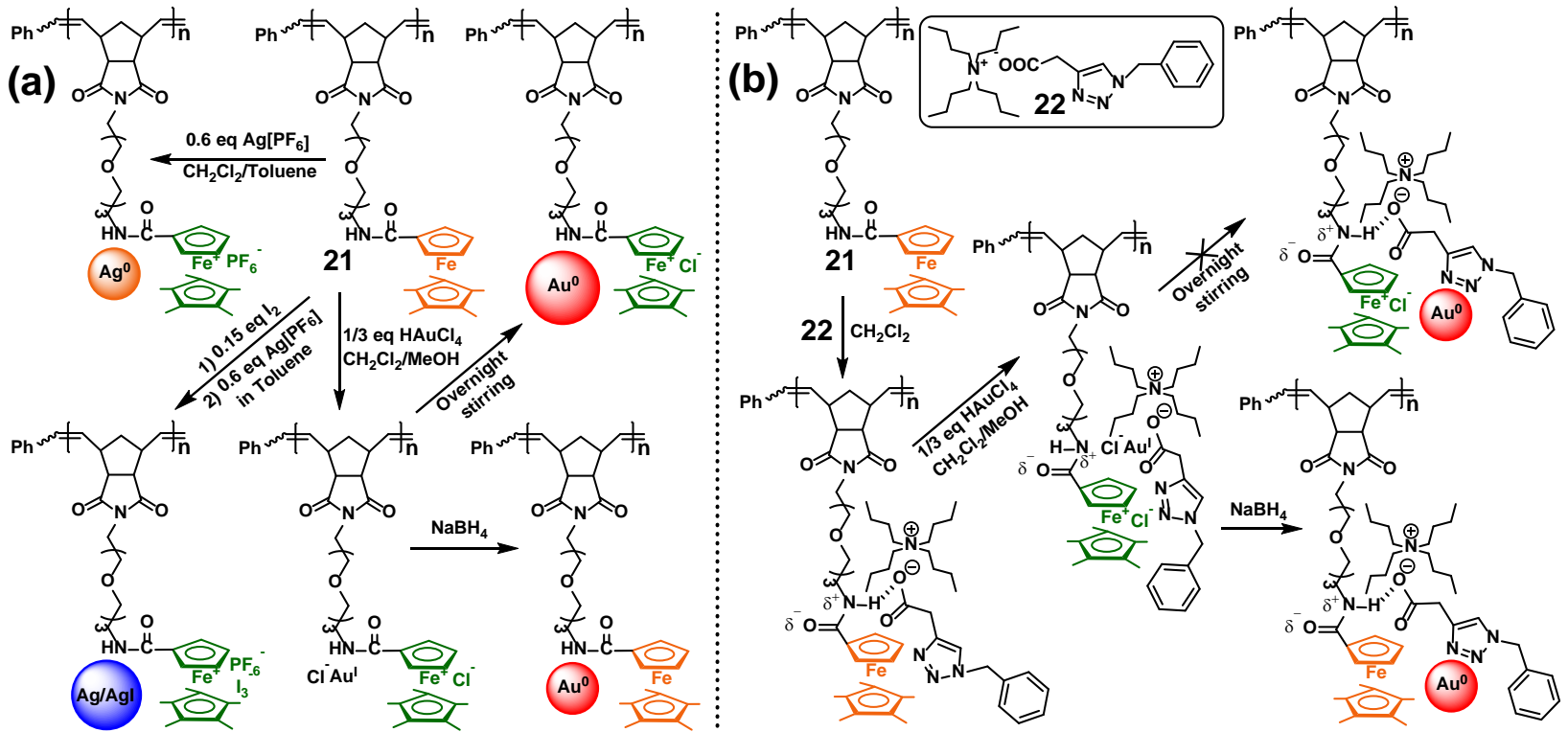

Fig.9 (a) Preparation of various metal NPs. (b) Preparation of AuNPs in the presence of the triazole ligand 22.
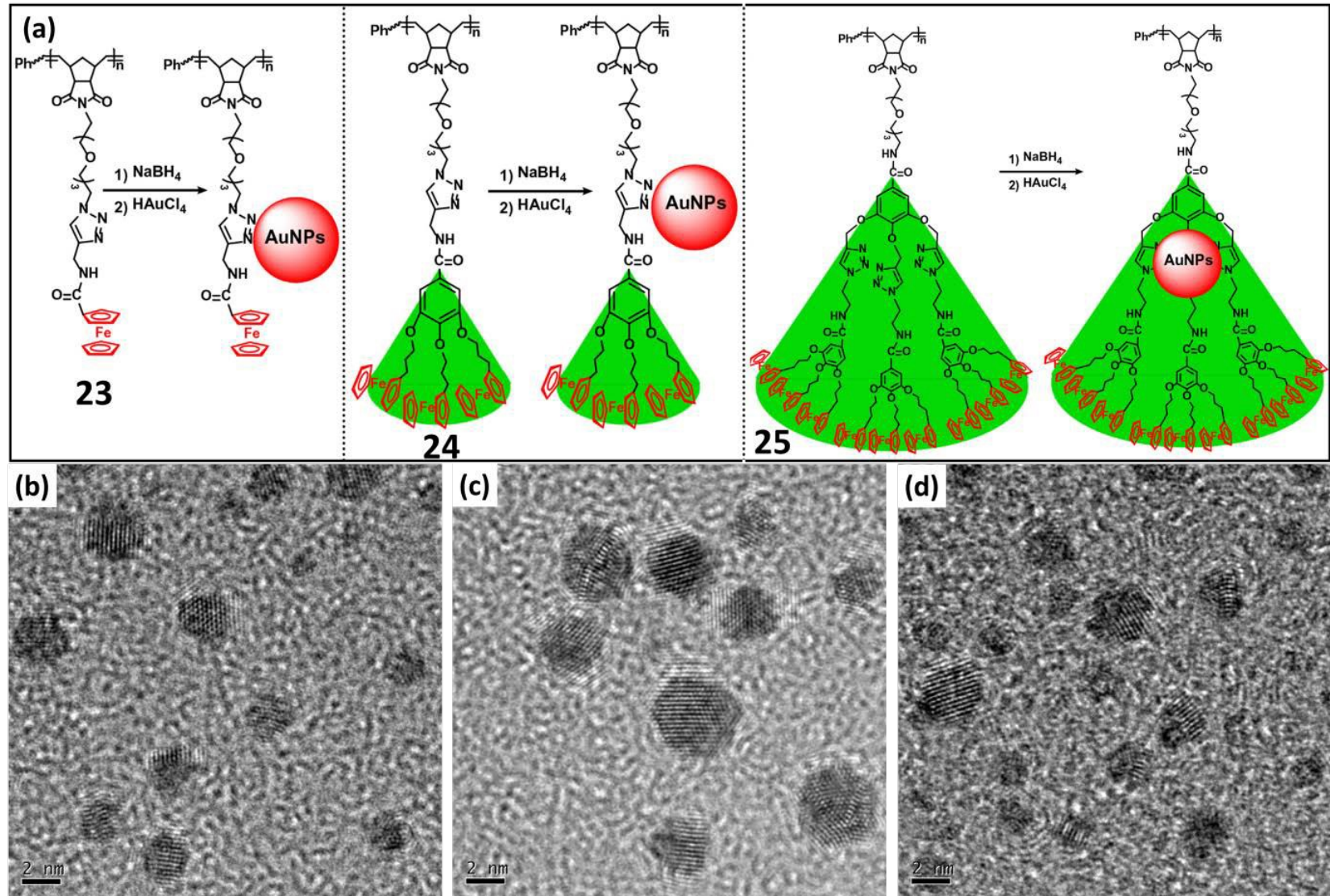

Fig. 10. (a) Preparation of AuNPs using 23, 24 and 25, respectively, as stabilizers. HRTEM images of AuNPs stabilized by 23 (b), 24 (c) and 25 (d), respectively. Reproduced with permission from ref 60. Copyright 2018 Elsevier. 

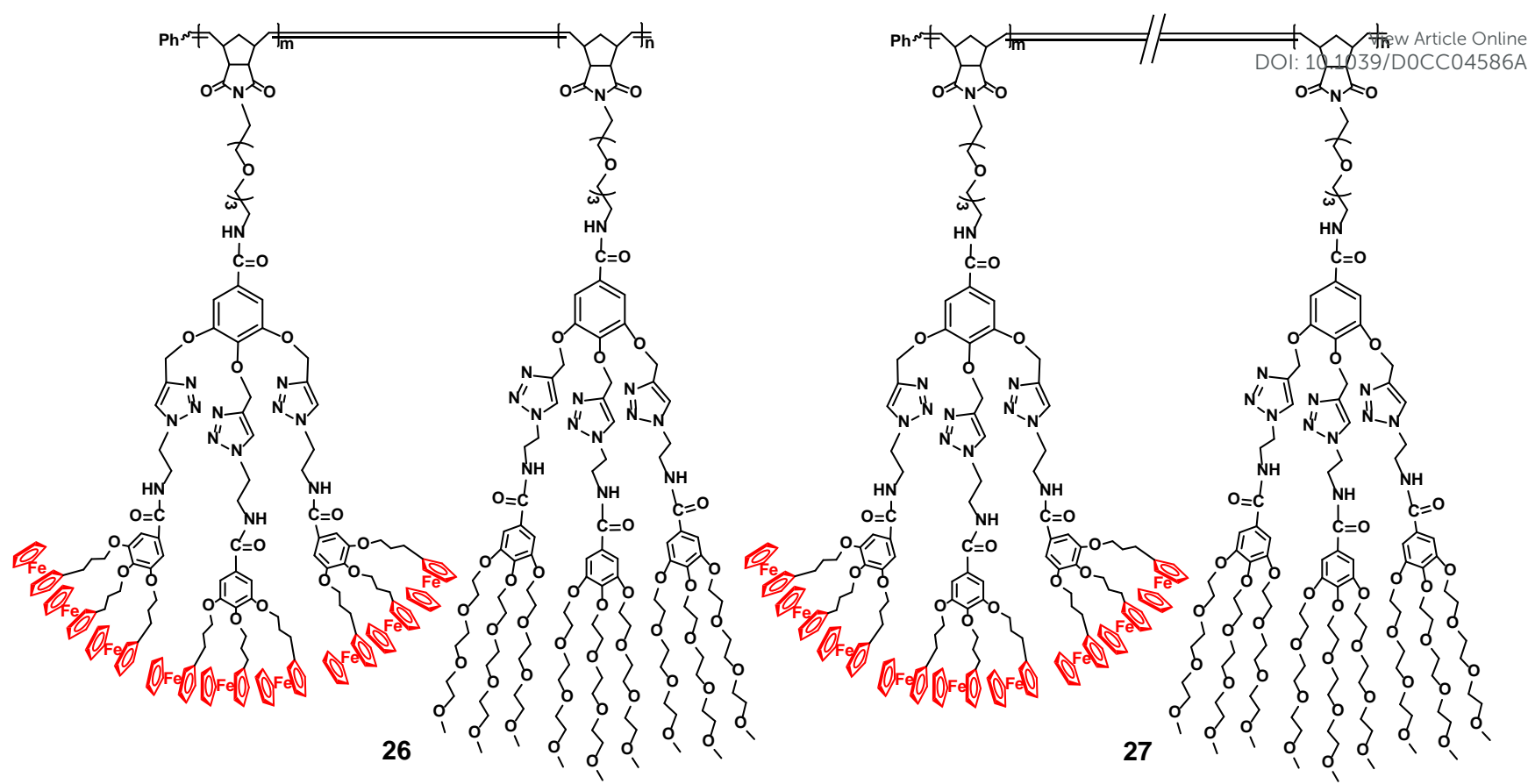

Fig. 11. Molecular structures of $\mathbf{2 6}$ and 27.

addition of $\mathrm{NaBH}_{4}$ was necessary, resulting in formation of AuNPs $(11 \pm 2 \mathrm{~nm}) . .^{52}$

Even smaller stable AuNPs were obtained upon stabilization by the "click" triazole ligand in monomeric or polymeric structures containing ferrocene groups. ${ }^{57}$ This triazole ligand presents remarkable properties in catalysis ${ }^{58}$ that are still much enhanced with triazolyl-containing tripodal dendrons presenting encapsulation properties. ${ }^{59}$ Thus, by reaction of $\mathrm{HAuCl}_{4}$ with the polymers 23, $\mathbf{2 4}$ and $\mathbf{2 5}$ containing tri- or nonaferrocene dendrons, a range of small AuNPs (approximately $2.0 \mathrm{~nm}$ ) formed in $\mathrm{CH}_{2} \mathrm{Cl}_{2}$ solution (Fig. 10). ${ }^{60}$ Subsequently, these resulting polymerencapsulated AuNPs were used as efficient catalysts in biphasic $\left(\mathrm{CH}_{2} \mathrm{Cl}_{2} / \mathrm{H}_{2} \mathrm{O}\right)$ systems for the reduction of $4-\mathrm{NP}$ to $4-\mathrm{AP} .{ }^{61}$ The catalytic results indicated that polymer $\mathbf{2 4}$ was the optimal stabilizer of AuNPs for the 4-NP reduction in this heterogeneous system compared to polymers $\mathbf{2 3}$ or $\mathbf{2 5}$. AuNPs stabilized by $\mathbf{2 4}$ were recyclable and reused at least twenty times. In addition, it was also found that amphiphilic block copolymer $\mathbf{2 6}$ and random copolymer 27 (Fig.11) self-assembled into spherical micelles in aqueous solution, which provided an advantage to stabilize noble metal NPs. ${ }^{62,63}$ The amphiphilic copolymers $\mathbf{2 6}$ and $\mathbf{2 7}$ stabilized AuNPs (approximately $2.0 \mathrm{~nm}$ ) to form efficient homogeneous catalysts for the 4-NP reduction in aqueous solution. The dendronized polymerencapsulated AuNPs had turnover numbers (TONs) up to 25000 and turnover frequencies (TOFs) of $26400 \mathrm{~h}^{-1}$ in the reduction of 4$\mathrm{NP}$, and were stable and highly efficiency for at least two months. ${ }^{63}$

\subsection{Biomedical Applications: Hydrogels, Antibacterial Nanoparticles, and Drug Carriers}

Metal-sandwich complex-containing hydrogels are becoming increasingly used in the fabrication of biomedical, shape-memory and self-healing materials. ${ }^{64}$ Recently, a ferrocene- and aldehydecontaining tetrablock copolymer $\mathbf{2 8}$ (Fig.12) was synthesized by

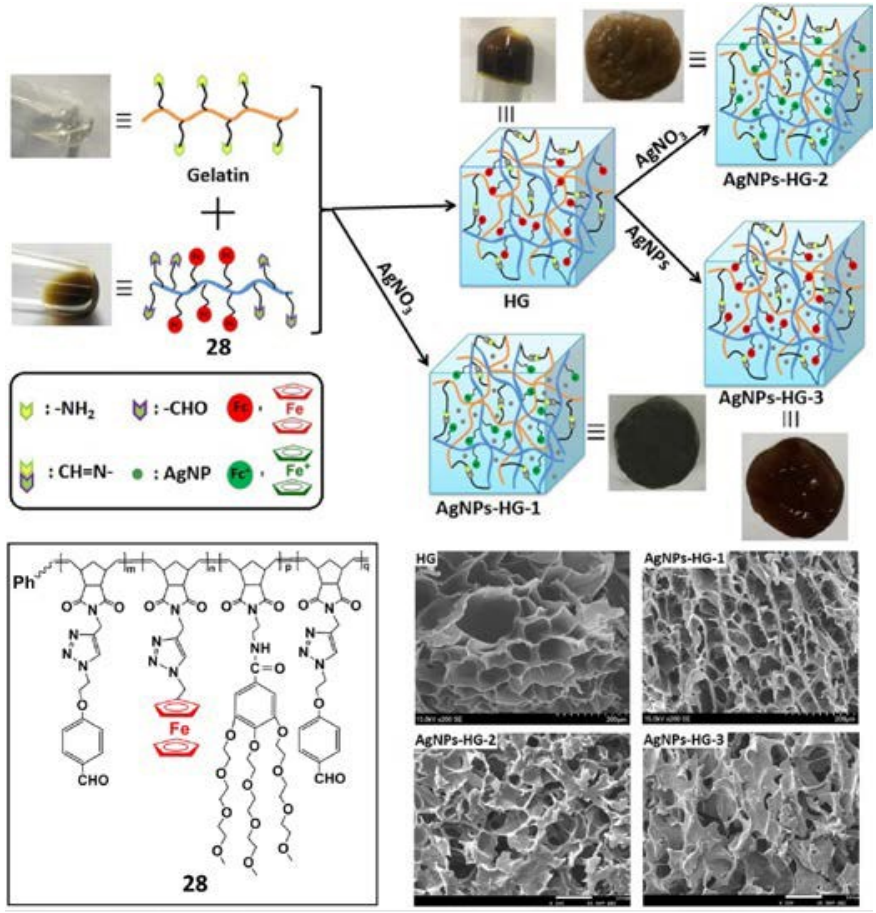

Fig. 12 Fabrication routes of various gelatine hydrogels cross-linked by $\mathbf{2 8}$ and their photographs and SEM images. Reproduced with permission from ref 65. Copyright 2019 Elsevier.

ROMP. It was used to cross-link gelatine through the Schiff-base interaction between the aldehyde moieties of $\mathbf{2 8}$ and the side-chain amino groups of gelatine, resulting in the generation of a Fccontaining gelatine hydrogel $(\mathrm{HG}){ }^{65}$ Due to the reducing properties of THE ferrocene units and the mild stabilization of NPs by triazole, 28 was adopted to reduce $\mathrm{Ag}(\mathrm{I})$ and stabilize the AgNPs formed. Based on these properties, two strategies were further successfully 


\section{ARTICLE}

(a)

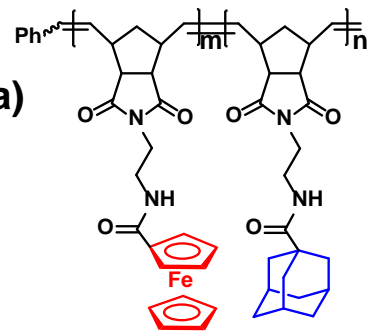

29

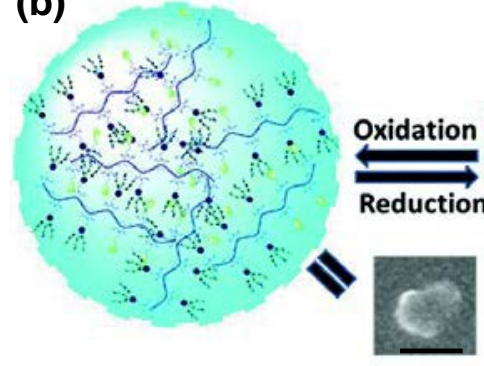

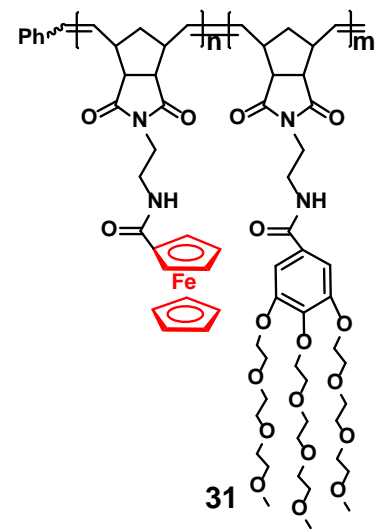
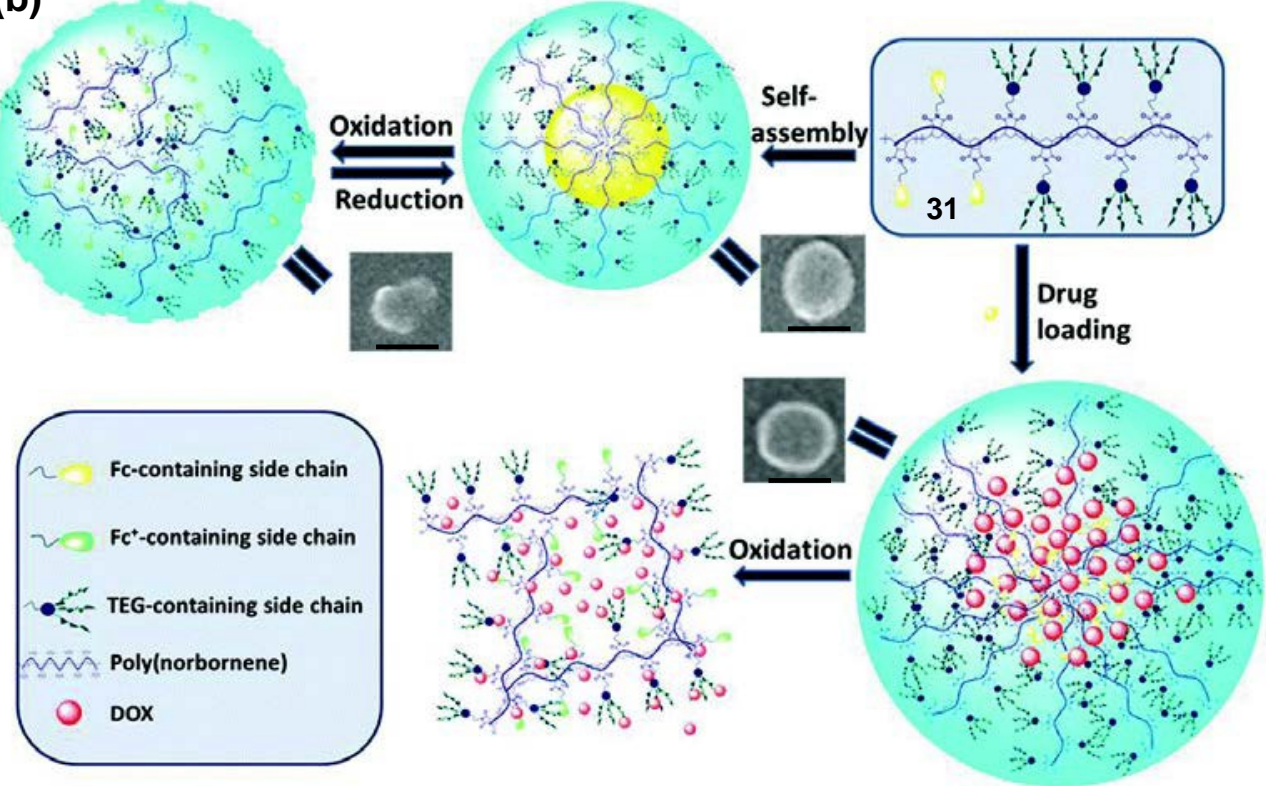

Fig. 13 (a) Molecular structures of ferrocene-based polymers 29, 30 and 31. (b) Schematic illustration of the redox-controlled micelles of $\mathbf{3 1}$ as drug carriers; the SEM images of the corresponding micelles are inserted (scale bar: $100 \mathrm{~nm}$ ). Reproduced with permission from ref 68. Copyright 2019 Royal Society of Chemistry.

adopted to fabricate hybrid composite AgNP hydrogels (Fig. 12). In the blending method, gelatine, 28 and $\mathrm{AgNO}_{3}$ were mixed to prepare the composite AgNPs hydrogel (AgNPs-HG-1), and both the formation of AgNPs via Fc-based reduction and hydrogel networks cross-linked via Schiff-base reaction proceeded at the same time. In the soaking route, the composite AgNPs hydrogel (AgNPs-HG-2) was synthesized through simple immersion of the $\mathrm{HG}$ into an $\mathrm{AgNO}_{3}$ aqueous solution leading to the in-situ generation of AgNPs in the hydrogel matrix. Besides, the AgNPs-HG-3 hydrogel was also fabricated via immersing HG into the AgNPs solution. Antibacterial tests indicated that the resulting AgNPs-containing hydrogels showed good antibacterial abilities towards E. coli and S. aureus. ${ }^{65}$
Ferrocene-based polymers have recently aroused widespread concern for the construction of redox-responsive drug carriers because of the characteristic redox chemistry of the ferrocenyl groups. ${ }^{21,24,66}$ Primarily inspired by the host-guest combination between $\beta$-cyclodextrin ( $\beta-C D)$ and adamantane or ferrocene units, the ferrocene- and adamantane-bearing diblock copolymer 29 (Fig. 13a) was prepared by ROMP and formed an amphiphilic supramolecular polymer upon simple mixing $\beta-C D$ with an equimolar quantity to side-chain adamantane groups. ${ }^{67}$ The resulting amphiphilic supramolecular polymer showed a redoxresponsive self-assembly behaviour and formed redox-responsive micellar carriers for the drug benzocaine. Moreover, the amphiphilic dendronized polymer $\mathbf{3 0}$ (Fig. 13a) self-assembled to 
generate spherical micelles that showed reversibly redoxresponsive behaviour using $\mathrm{FeCl}_{3}$ as an oxidant and glutathione as a reductant. ${ }^{52}$ Thereafter, the resulting micelles were successfully employed as redox-controlled carriers for the load and release of the model molecule Rhodamine B. More importantly, an amphiphilic diblock copolymer 31 (Fig.13a) encapsulated the anticancer drug doxorubicin (DOX) to generate DOX-loaded micelles that showed oxidation-triggered drug release behaviour (Fig. 13b). ${ }^{68}$ Cytotoxicity test and model organism (zebra fish embryo) studies verified the excellent biocompatibility and safety of copolymer $\mathbf{3 1}$. Therefore, amphiphilic copolymer $\mathbf{3 1}$ shows potential applications toward targeted drug delivery for cancer therapy.

\section{Conclusion and outlook}

This Feature Article has discussed the engineering and multiple applications of metallopolymers containing Electron-Reservoir complexes, that is metal-sandwich complexes that are robust in at least two redox states including their reduced neutral and oxidized cationic forms. In a large majority of cases, ferrocenes were involved, but in many useful examples the ferricenium form is stabilized in a mixed-valence biferrocenium cation, in a pentamethylcyclopentadienyl derivative or by a heteroatom as a ferricenium substituent. Both families of polymers containing the Electron-Reservoir system either in the main polymer chain or located on the side branch of the polymer have provided a large number of applications, but the family involving ${ }^{14}$ redox systems and other groups on the side arm synthesized by ROMP gives precise and well-controlled polymers allowing the controlled introduction of several blocks. This latter strategy is more sophisticated and favourable toward the design, for instance, of electrochromic systems with up to five distinct colours or to control the solubility by the introduction of a specific solubilizing group or cross-linking toward hydrogels. Goodenough pioneered the application of ferrocene-containing polymers in battery application, ${ }^{14}$ but more robust ferrocene-type redox system should soon prove more promising.

Electron-Reservoir complexes were well known for their applications as stoichiometric and catalytic redox reagents, ${ }^{24,27}$ in particular their use as redox catalysts, electrocatalysts and electrochemical references. Their incorporation in polymers with controlled solubility and processability now allows extension of their application to polymeric materials. These Electron-Reservoir complexes were also incorporated in dendrimers that are rather sophisticated, ${ }^{17,28,29}$ but applications in both categories of macromolecules are quite distinct due to differences of topology and accessibility. Polycationic metallocenium polymers are also potentially useful polyelectrolytes. ${ }^{69-71}$ Continued progress in such metallopolymer engineering should, in the future, bring about new applications for electric conductors and semi-conductors, battery nanocomponents, electrocatalysts, polyelectrolytes, plasmonic properties, spin cross-over-based memories, ${ }^{72}$ fullerenes, drug carriers, sensors, actuators, and multiproperty nanomaterials. ${ }^{1-24}$

\section{Conflicts of interest}

There are no conflicts to declare.

\section{Acknowledgements}

Financial Support by the Universite de Bordeaux, the Centre National de la Recherche Scientifique (CNRS), the National Natural Science Foundation of China (No. 21978180), the Science \& Technology Department of Sichuan Province (No. 2018HH0038), Sichuan University at Chengdu for invited professorship to DA, ceshigo (www.ceshigo.com) and L'Oréal Research Center at Aulnay-sous-Bois, France, are gratefully acknowledged. We also appreciate the valuable help of Dr. Wang Hui (Analytical \& Testing Center of Sichuan University).

\section{Biographies}

Xiong Liu received his bachelor degree from Wuhan University of Technology. Now, he is a PhD student at Sichuan University under the supervision of Dr. Haibin Gu. His research interest is the synthesis and application of ferrocene-containing polymers and the related functional materials, and he has published around 20 articles, especially in ferrocene-containing polymers.

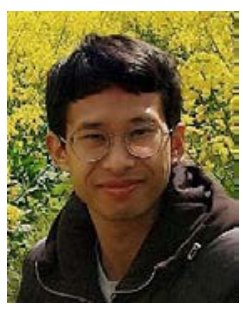

Amalia Rapakousiou studied at the National and Kapodistrian University of Athens (Greece), then at the University of Bordeaux where she worked during her undergraduate and $\mathrm{PhD}$ degrees under the supervision of Professor Didier Astruc on redox nanomaterials including metallomacromolecular Electron-Reservoir complexes. Then she held post-doctoral research fellowship positions in the laboratory of Professor Hiroshi Nishihara at the University of Tokyo, Japan (J.S.P.S. fellowship), at the IMDEA Nanoscience Institute in Madrid (Juan-de-la-Cierva grant), and since 2019 at the Laboratory of Coordination Chemistry of the CNRS in Toulouse, France ('Make-our-planet-great-again' M.O.P.G.A grant). Her research focuses on the engineering, control and applications of macromolecule-based nanocomposites.

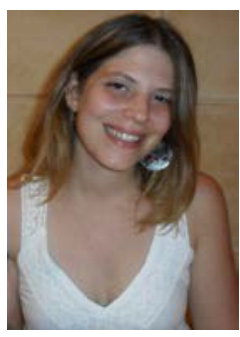


Christophe Deraedt received his master's degree, then his PhD at the University of Bordeaux as a Ministry of Research Awardee where he worked with Professor Didier Astruc on the synthesis and uses of green dendrimer and polymer nanoreactors in nanocatalysis. In 2016, he started postdoctorate studies in the Gabor Somorjai group at the University of California at Berkeley on the heterogenization of homogeneous catalysts for $\mathrm{C}-\mathrm{C}$ and $\mathrm{C}-\mathrm{H}$ bond activation, and dehydrogenation reactions. After another post-doctoral stay as a teacher in the group of Professor Frederic Castet at the University of Bordeaux on theoretical chemistry, he joined the group of Jean-Pierre Djukic in the University Louis Pasteur at Strasbourg as a CNRS permanent researcher in January 2019. His work is now focused on the activation of $\mathrm{C}-\mathrm{H}$ and $\mathrm{Si}-\mathrm{H}$ bonds with $3 \mathrm{~d}$ metals.

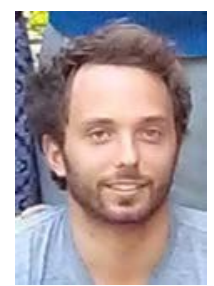

Roberto Ciganda prepared his PhD at the Universidad del País Vasco (UPV/EHU), San Sebastian, Spain on hydrogen evolution catalyzed by noble metal complexes under the supervision of Professor Maria Ángeles Garralda. He did a two-year postotoral study at the Université of Bordeaux in the group of Professor Didier Astruc on the redox and electrochemical studies of metallopolymers and block copolymers. He then returned to San Sebastian for another post-doctoral study with $\mathrm{Dr}$ Ricardo Hernandez on metallopolymers and nanocatalysis.

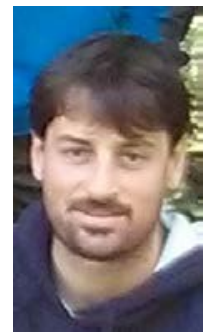

Haibin Gu received his PhD from Sichuan University in 2008. He was then a lecturer at Sichuan University from 2008 to 2012, and later spent two years as a visiting scholar at University of Bordeaux with Professor Didier Astruc. He is currently an Associate Professor at Sichuan University, and his interests are the preparation of metallocene-containing polymers and their applications including catalysis, functional materials and nanomedicine. He has published more than 70 research articles, especially in metallocene-containing polymers.

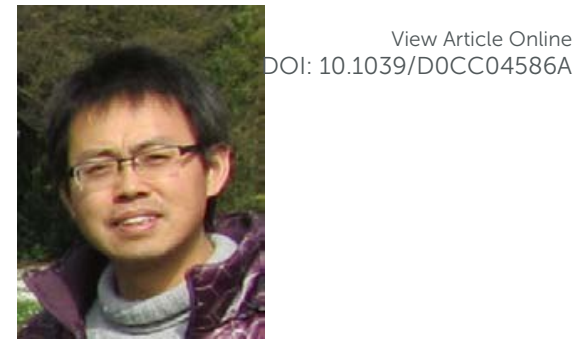

Didier Astruc was born in Versailles and studied in Rennes where he passed his doctorates, then he was a NATO postdoctoral fellow at MIT, Cambridge (USA), and later spent a sabbatical year in the University of California at Berkeley. He is Professor of chemistry in Bordeaux and Member of the Institut Universitaire de France and several national and European academies. He also is an invited professor at the Sichuan University at Chengdu. Jaime Ruiz obtained a Master degree in the Catholic University, Santiago de Chile, did hid PhD in the University of Bordeaux and a post-doc in the University of Texas at Austin, then returned to Bordeaux where he was a research engineer and conducted synthetic and electrochemical studies.

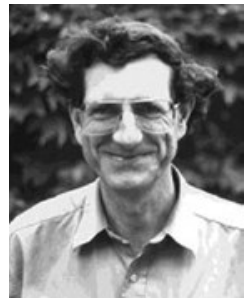

\section{Notes and references}

Present addresses. "A.R.: Laboratoire de Chimie de Coordination du CNRS, 205 route de Narbonne, 31400, Toulouse, France. E-mail: amalia.rapakousiou@lcc-toulouse.fr; § C. D. LCSOM, UM7177, Institut Le Bel, Université Louis Pasteur, 1 rue Blaise Pascal, FR67008 Strasbourg, France. E-mail : deraedt@unistra.fr; ${ }^{\text {}}$ Y. W. : Liaocheng University, Department of Chemistry and Chemical Engineering, 252059, Liaocheng, China. E-mail: wangyanlan@lcu.edu.cn.

1 J. F. Lutz, J. M. Lehn, E. W. Meijer and K. Matyjaszewski, Nat. Rev. Mater., 2016, 1, UNSP 16024.

2 S. Gao, G. Tang, D. Hua, R. Xiong, J. Han, S. Jiang, Q. Zhang and C. Huang, J. Mater. Chem. B, 2019, 7, 709-729.

3 G. C. Vougioukalakis and R. H. Grubbs, Chem. Rev., 2010, 110, 1746-1787.

4 J. Zhou, G. R. Whittel and I. Manners, Macromolecules, 2014, 47, 3529-3543.

5 A. S. Abd-El-Aziz and E. A. Srohm, Polymer, 2012, 53, 48794921.

6 L. Hu, Y. Wan, Q. Zhang and M. J. Serpe, Adv. Funct. Mater., 2020, 30, 1903471.

7 P. H. Zhang, D. Gao, K. L. An, Q. Shen, C. Wang, Y. C. Zhang, X. S. Pan, X. G. Chen, Y. F. Lyv, C. Cui, T. X. Z. Liang, X. M. 
Duan, J. Liu, T. L. Yang, X. X. Hu, J. J. Zhu, F. Xu and W. H. Tan, Nat. Chem. 2020, 12, 381-390.

8 S. M. Jung and H. J. Yoon, Angew. Chem. Int. Ed., 2020, 59, 4883-4887.

9 J. M. McCracken, B. R. Donovan and T. J. White, Adv. Mater. 2020, 32, 1906564.

10 I. Dragutan, V. Dragutan, B. Siminescu, A. Demonceau and H. Fischer, Beilstein J. Org. Chem., 2015, 11, 2747-2762.

11 R. L. N. Hailes, A. M. Oliver, J. Gwyther, G. R. Whittel and I. Manners, Chem. Soc. Rev., 2016, 45, 5338-5407.

12 R. Pietschnig, Chem. Soc. Rev., 2016, 45, 5216-5231.

13 M. Gallei and C. Rujttiger, Chem. Eur. J., 2018, 24, 1000610021.

14 K. S. Pazk, S. B. Schuggard and J. B. Goodenough, Adv Mater., 2007, 19, 848-851.

15 L. Ma, Y. L. Liu, Y. Liu, S. Y. Jiang, P. Li, Y. C. Hao, P. P. Shao, A X. Yin, X. Feng and B. Wang, Angew. Chem. Int. Ed., 2019, 58, 4221-4226.

16 O. Mergel, S. Schneider, R. Tiwari, P. T. Kun, D. Keskin, M. C. A. Stuart, S. Schottner, M. de Kanter, M. Noyong, T. Caumanns, J. Mayer, C. Janzen, U. Simon, M. Gallei, D. Woll, P. van Rijn and F. A. Plamper, Chem. Sci., 2019, 10, 18441856.

17 M. Casado, B. Alonso, J. Losada and M. P. Garcia-Armada, Redox-active polymers and dendrimers as electrochemical sensors. In Designing Dendrimers. S. Campagna, P. Ceron and F. Eds. Puntoriero, Wiley, Hoboken, NJ, 2012, 219-262.

18 Z. L. Li, G. L. Li,; L. H. Jang,; J. L. Li, G. Q. Sun, C. G. Xia and F. W. Li, Angew. Chem. Int. Ed., 2015, 54, 1494-1498.

19 S. Wang, Z. Q. Xu, T. T. Wang, T. X. Xiao, X. Y. Hu, Y. Z. Shen and L. Y. Wang, Nat. Commun., 2018, 9, 1737.

20 A. S. Abd-El-Aziz, C. Agatemor and N. Etkin, Biomaterials, 2017, 118, 27-50.

21 C. Ornelas, New. J. Chem., 2011, 35, 1973-1985.

22 A. Harada, Y. Takashima and M. Nakahata, Acc. Chem. Res., 2014, 47, 2128-2140.

23 C. Ornelas, J. Ruiz, C. Belin and D. Astruc, J. Am. Chem. Soc., 2009, 131, 590-601.

24 D. Astruc, Eur. J. Inorg. Chem., 2017, 1, 6-29.

25 J. R. Aranzaes, M. C. Daniel and D. Astruc, Can. J. Chem. 2006, 84, 288-299.

26 L. Zhao, X. Liu, L. Zhang, G. R. Qiu, D. Astruc and H. B. Gu, Coord. Chem. Rev., 2017, 337, 34-79.

27 M. H. Desbois, D. Astruc, J. Guillin, F. Varret, A.X. Trautwein and G. Villeneuve, J. Am. Chem. Soc., 1989, 111, 5800-5809.

28 D. Astruc, C. Ornelas and J. Ruiz, Acc. Chem. Res., 2008, 41, 841-856.

29 D. Astruc, Nat. Chem., 2012, 4, 255-267.

30 C. Deraedt, A. Rapakousiou, Y. Wang, L. Salmon, M. Bousquet and D. Astruc, Angew. Chem., Int. Ed., 2014, 52, 8445-8449.

31 A. Rapakousiou, C. Deraedt, H. B. Gu, L. Salmon, C. Belin, J. Ruiz and D. Astruc, J. Am. Chem. Soc., 2014, 136, 1399513998.

32 T. Y. Dong, S. W. Chang, S. F. Lin, Y. S. Wen and L. Lee, Organometallics, 2006, 25, 2018-2024.

$33 \mathrm{M}$. Lohan, F. Justaud, H. Lang and C. Lapinte, Organometallics, 2012, 31, 3565-3574.

34 L. A. Canalle, S. S. van Berkel and L. T. de Haan, Adv. Funct. Mater., 2009, 19, 3464-3470.

35 V. V. Rostovtsev, L. G. Green, V. V. Fokin and K. B. Sharpless, Angew. Chem., Int. Ed., 2002, 114, 2596-2599.

36 J. B. Flanagan, S. Margel, A. J. Bard and F. C. Anson, J. Am. Chem. Soc., 1978, 100, 4248-4253.

37 P. D. Beer and P. A. Gale, Angew. Chem. Int. Ed., 2001, 40, 486-516.

38 P. D. Beer, P. A. Gale and G. Z. Chen, Coord. Chem. Rev., 1999, 85-86, 3-36
39 N. H. Evans and P. D. Beer, Angew. Chem. Int. Ed, 2014 53 11716-11754.

DOI: 10.1039/DOCC04586A

$40 \mathrm{H}$. Wang, X. Wang, M. A. Winnick and I. Manners, J. Am. Chem. Soc., 2008, 130, 12921-12930.

41 L. E. Wilson, C. Hassenruck, R. F. Winter, A. J. P. White, T. Albecht and N. J. Long, Angew. Chem., Int. Ed., 2017, 56, 6838-6842.

42 E. Boisselier, A. C. K. Shun, J. Ruiz, E. Cloutet, C. Belin and D. Astruc, New J. Chem., 2009, 33, 246-253.

43 X. Liu, W. Lin, D. Astruc and H. B. Gu, Prog. Polym. Sci., 2019, 96, 43-105.

44 C. X. Hua, H. B. Xu, S. Hou, L. Shang, S. L. Dou, Y. C. Zheng, P. P. Zhang, Y. Gan, J. P. Zhao and Y. Li, Chem. Eng. J., 2019, 360, 591-599.

45 H. B. Gu, R. Ciganda, P. Castel, S. Moya, R. Hernandez, J. Ruiz and D. Astruc, Angew. Chem. Int. Ed., 2018, 57, 2204-2208.

46 R. Hein, P. D. Beer and J. J. Davies, Chem. Rev., 2020, 120, 1888-1935.

47 C. Valério, J. L. Fillaut, J. Ruiz, J. Guittard, J. C. Blais and D. Astruc, J. Am. Chem. Soc., 1997, 119, 2588-2589.

48 A. J. Bard and L. R. Faulkner. Electrochemical Methods: Fundamentals and Applications, 2nd Ed., Wiley, New-York, 2000.

49 H. D. Abruña, Coord. Chem. Rev., 1988, 86, 135-189.

50 W. E. Geiger. Organometallics, 2007, 26, 5738-5765.

51 H. B. Gu, A. Rapakousiou, P. Castel, N. Guidolin, N. Pinaud, J. Ruiz and D. Astruc, Organometallics, 2014, 33, 4323-4335.

52 H. B. Gu, R. Ciganda, P. Castel, A. Vax, D. Gregurec, J. Irigoyen, S. Moya, L. Salmon, P. X. Zhao, J. Ruiz, R. Hernández and D. Astruc, Chem. Eur. J., 2015, 21, 18177-18186.

53 A. Rapakousiou, C. Deraedt, J. Irigoyen, Y. Wang, N. Pinaud, L. Salmon, J. Ruiz, S. Moya, J. Ruiz and D. Astruc, Inorg. Chem., 2015, 54, 2284-2299.

54 R. Ciganda, H. B. Gu, R. Hernández, A. Escobar, A. Martínez, L. Yate, S. Moya, J. Ruiz and D. Astruc, Inorg. Chem., 2017 56, 2784-2791.

55 Q. Wang, F. Fu, A. M. Martinez-Villacorta, S. Moya, L. Salmon, A. Vax, J. Hunel, J. Ruiz and D. Astruc, Chem. Eur. J., 2018, 24, 12686-12694.

56 N. Li, P. Zhao and D. Astruc, Angew. Chem., Int. Ed., 2014, 52 1756-1789.

57 N. Li, P. Zhao, N. Liu, M. E. Igartua, S. Moya, L. Salmon, J. Ruiz and D. Astruc, Chem. Eur. J., 2014, 20, 8363-8369.

58 D. Huang, P. Zhao and D. Astruc, Coord. Chem. Rev., 2014, 272, 145-165.

59 C. Wang, R. Ciganda, L. Salmon, D. Gregurec, J. Irigoyen, S. Moya, J. Ruiz and D. Astruc, Angew. Chem. Int. Ed., 2016, 55, 3091-3095.

60 F. F. Liu, X. Liu, D. Astruc and H. B. Gu, J. Colloid Interface Sci., 2019, 533, 161-170.

61 P. Zhao, X. Feng, D. Huang, G. Yang and D. Astruc, Coord. Chem. Rev., 2015, 287, 114-136.

62 X. Liu, F. F. Liu, D. Astruc, W. Lin and H. B. Gu, Polymer, 2019 173, 1-10.

63 X. Liu, F. F. Liu, Y. L. Wang and H. B. Gu, React. Funct. Polym. 2019, 143, 104325 .

64 M. F. Ni, N. Zhang, W. Xia, X. Wu, C. H. Yao, X. Liu, X. Y. Hu, C. Lin and L. Y. Wang, J. Am. Chem. Soc., 2016, 138, 6643-6649.

65 S. D. Mu, W. T. Liu, L. Zhao, Y. R. Long and H. B. Gu, Polymer, 2019, 169, 80-94.

66 H. B. Gu, S. D. Mu, G. R. Qiu, X. Liu, L. Zhang, Y. F. Yuan and D. Astruc, Coord. Chem. Rev., 2018, 364, 51-85.

67 L. Zhang, G. R. Qiu, F. F. Liu, X. Liu, S. D. Mu, Y. R. Long, Q. X. Zhao, Y. Liu and H. B. Gu, React. Funct. Polym., 2018, 132, 6073.

68 G. R. Qiu, X. Liu, B. R. Wang, H. B. Gu and W. X. Wang, Polym. Chem., 2019, 10, 2527-2539. 
69 U. F. J. Mayer, J. B. Gilroy, D. O'Are and I. Manners, J. Am. Chem. Soc., 2009, 131, 13382-10383.

70 M. A. Rahman, Y. J. Cha, L. Yuan, P. Pageni, T. Y. Zhu, M. S. Jui and C. B. Tang, J. Polym. Sci., 2020, 58, 77-83.

71 Y. Wang, A. Rapakousiou and D. Astruc, Macromolecules, 2014, 47, 3767-3774.

72 G. Molnar, S. Rat, L. Salmon, W. Nicolazzi and A. Bousseksou. Adv. Mater. 2018, 30, 17003862.

\section{TOC:}

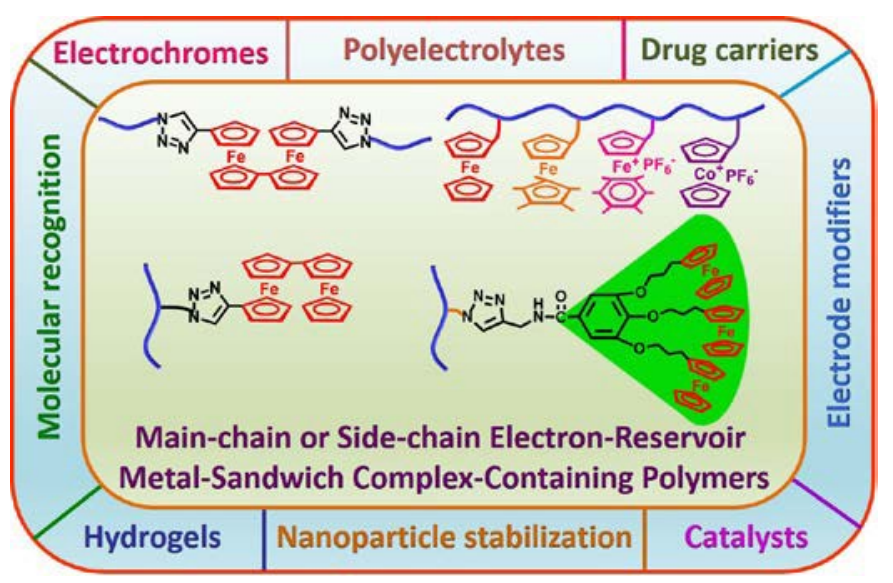


TOC:

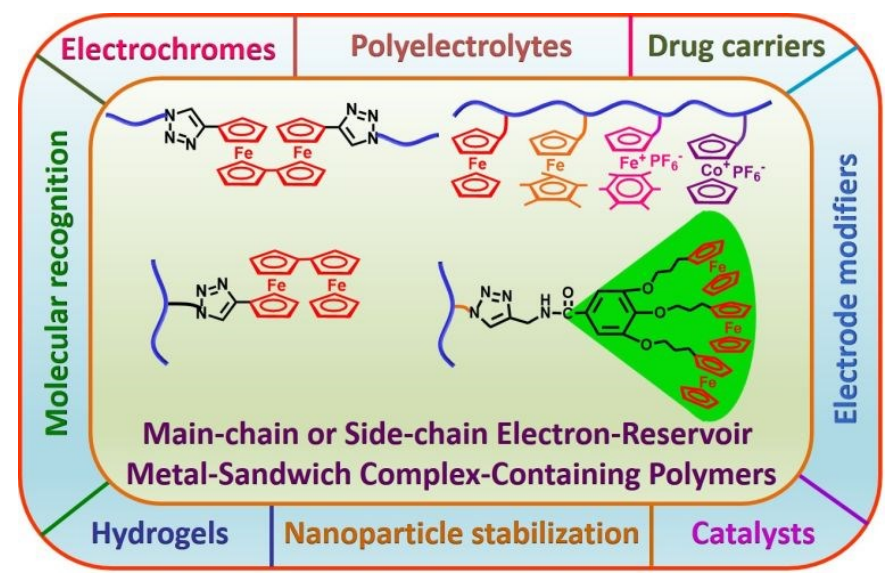

Polymers containing redox-robust first-row late-transition-metal complexes, essentially of ironsandwich type, are shown to provide a variety of engineered properties and nanomaterials applications illustrated in the graph. 